\title{
Selective detection of cysteine at a mesoporous silica film electrode functionalized with ferrocene in the presence of glutathione
}

\author{
Mr. Himanshu Maheshwari, Dr. Neus Vilà, Dr. Grégoire Herzog,* Dr. Alain Walcarius* \\ Laboratoire de Chimie Physique et Microbiologie pour les Matériaux et l'Environnement (LCPME), \\ UMR 7564, Université de Lorraine - CNRS, 405 Rue de Vandoeuvre, 54600 Villers-lès-Nancy, France \\ *Corresponding author: alain.walcarius@univ-lorraine.fr, gregoire.herzog@univ-lorraine.fr
}

\begin{abstract}
Unmodified and ferrocene-functionalised mesoporous silica layers exhibiting vertical nanochannels have been grown by electrochemically assisted self-assembly onto indium-tin oxide (ITO) and the resulting film electrodes have been applied to the electrochemical detection of cysteine. When using the unmodified film electrode and ferrocenedimethanol $\left(\mathrm{Fc}(\mathrm{MeOH})_{2}\right)$ as mediator in solution, both cysteine and glutathione can be oxidised by $\mathrm{Fc}(\mathrm{MeOH})_{2}{ }^{+}$generated at the electrode surface but the electron transfer rates were three times faster with cysteine than with glutathione. This can be exploited for the reagent-free selective detection of cysteine over glutathione by using a ferrocene-functionalised mesoporous silica film on ITO electrode, based on a combination of charge transfer kinetic and mass transport limitations through the oriented nanochannels. This has been demonstrated here by cyclic voltammetry and amperometry in a flow injection analysis mode. A sensitivity of $1.28 \mathrm{~mA} \mathrm{M}^{-1}$ was measured for the cysteine concentration range of 3- $20 \mu \mathrm{M}$ with a repeatability of the signal between 3 and $12 \%$. The lowest concentration of cysteine experimentally detected was $3 \mu \mathrm{M}$.
\end{abstract}




\section{Introduction}

Thiol molecules, such as cysteine, play an important role as antioxidants in physiological fluids. ${ }^{[1,2]}$ Cysteine concentration in whole blood is generally in the sub-millimolar range. ${ }^{[3]}$ As its concentration variation has been correlated with a variety of disease, the monitoring of cysteine in physiological fluids could be used as a diagnostic of the evolution of several pathologies and clinical conditions. ${ }^{[4-9]}$ High levels of thiols in blood have been associated to cancer or diabetes, ${ }^{[5,8,9]}$ while high thiol concentrations were observed in patients suffering from Alzheimer and Parkinson disease. ${ }^{[4,6]}$

Cysteine is a molecule that can be electrochemically oxidised with a standard redox potential of $-0.22 \mathrm{~V}$ vs NHE. ${ }^{[10]}$ The overall electrochemical cysteine oxidation process leads to the formation of a disulfide bond as described in the reaction (1). ${ }^{[10]}$

$$
2 C y S H \rightarrow C y S S C y+2 H^{+}+2 e^{-}
$$

Due to low charge transfer kinetics at commonly used bare electrodes, overpotentials close to $+1 \mathrm{~V}$ were observed on gold, platinum and glassy carbon electrodes. ${ }^{[10]}$ Oxidation of thiols at such high potentials can lead to the oxidation of other molecules present in the solution and to the passivation of the electrode surface by reaction products, which limit the possibility of analytical applications. ${ }^{[11]}$ Boron-doped diamond ${ }^{[12]}$ and $\mathrm{FTO}^{[13]}$ electrodes were also used for the direct oxidation of cysteine and thiol compounds at lower overpotentials. However, the alkaline ${ }^{[12]}$ or acidic ${ }^{[13]}$ conditions limited their analytical applications. The overpotentials are partially overcome by the addition to the solution of a variety redox mediators, which include: nitrosophenyl, ${ }^{[14]}$ catechol, ${ }^{[15]}$ quinone, ${ }^{[16]}$ ferrocene derivatives, ${ }^{[17]}$ cyclotricatechylene. ${ }^{[18]}$ The electrode surface has also been modified to provide electrocatalytic properties in order to lower the thiol oxidation potential. The various strategies included the immobilisation of redox-active polymers such as Prussian blue, ${ }^{[19]}$ poly(3,4-ethylenedioxythiophene), ${ }^{[20,21]}$ poly(eugenol), ${ }^{[22]}$ caffeic acid-based polymer. ${ }^{[23]}$ Redox mediators were also trapped inside polymer matrix ${ }^{[24,25]}$ or sol-gel material ${ }^{[26]}$ for electrocatalytic thiol detection.

Electrodes modified with vertically aligned nanoporous silica membranes can be prepared by electrochemically assisted self-assembly (EASA) ${ }^{[27]}$ or by a Stöber solution growth. ${ }^{[28]}$ The EASA method, developed in our group, leads to the formation of silica membranes of a 
thickness ranging from 50 to $150 \mathrm{~nm}^{[29]}$ and with pore diameters tuneable between 2 and 3 $n m .{ }^{[30]}$ Organic moieties can be further introduced to the silica membranes. ${ }^{[31-33]}$ The interest of such mesoporous silica membranes for electrochemical sensing has raised in recent years. ${ }^{[34-37]}$ Mesopore diameters, ${ }^{[30]}$ membrane thickness, ${ }^{[38,39]}$ the solution $\mathrm{pH}$ and ionic strength, ${ }^{[40,41]}$ the surface charge of the pores, ${ }^{[37,42]}$ and the nature of the redox probes ${ }^{[43]}$ have a strong influence on the electroanalytical signal. Furthermore, vertically oriented mesoporous silica films have demonstrated permselective ion transport and molecular sieving properties. ${ }^{[30,35,44,45]}$ The negatively charged nature of the silica walls for $p H>3$ allowed the transport of cationic and neutral species but restricting anionic ones. ${ }^{[4,45]}$ Size selectivity was also demonstrated with molecular probes (ferrocene-functionalised dendrimers, ruthenium complexes and redox proteins), which dimensions were greater than the pore diameter. ${ }^{[30,46,47]}$

We have investigated the oxidation of two thiols of biological relevance, cysteine and glutathione, at electrodes modified with mesoporous silica films. In a first set of experiments, the thiols were electrocatalytically oxidised by the presence of ferrocenium derivatives generated at the electrode surface. The influence of the film on the thiol oxidation mediated by $\mathrm{Fc}(\mathrm{MeOH})_{2}$ was studied by a series of cyclic voltammetry experiments. In a second set of experiments, ferrocene groups were covalently attached to the silica walls. The immobilisation of the redox mediator induced the selectivity for cysteine over glutathione, as it was demonstrated by flow injection analysis.

\section{Materials and Methods}

\subsection{Chemicals and Reagents}

Tetraethoxysilane (TEOS, 98\%, Alfa Aesar), cetyltrimethylammonium bromide ( $\mathrm{C}_{16} \mathrm{TAB}, 99 \%$, Acros), ethanol (95-96\%, Merck), and $\mathrm{HCl}$ (1.0 M, Sigma-Aldrich) were used for the electrochemically assisted self-assembly (EASA) of mesoporous silica films on indium-dopedtin oxide (ITO) plates (surface resistivity 8-12 $\Omega \mathrm{cm}^{-2}$, Delta Technologies). Potassium ferrocyanide, $\left(\mathrm{K}_{4} \mathrm{Fe}(\mathrm{CN})_{6}, 99.5 \%\right.$, Fluka), 1,1'-ferrocene dimethanol $\left(\mathrm{C}_{12} \mathrm{H}_{14} \mathrm{FeO}_{2}, 97 \%\right.$, SigmaAldrich) and hexaammineruthenium(III) chloride $\left(\mathrm{Ru}\left(\mathrm{NH}_{3}\right)_{6} \mathrm{Cl}_{3}, 98 \%\right.$, Sigma-Aldrich) were used as redox probes in the cyclic voltammetry experiments. Cysteine, $\left(\mathrm{C}_{3} \mathrm{H}_{6} \mathrm{NO}_{2} \mathrm{~S},>97 \%\right.$, SigmaAldrich) and glutathione, $\left(\mathrm{C}_{10} \mathrm{H}_{17} \mathrm{~N}_{3} \mathrm{O}_{6} \mathrm{~S}, 98 \%\right.$, Acros $)$, were used as the analytes. 2,2- 
bis(hydroxymethyl)-2,2',2"--nitrotriethanol, $\left(\mathrm{C}_{8} \mathrm{H}_{19} \mathrm{NO}_{5}, 98 \%\right.$, Acros) was used as the buffer and sodium chloride $\left(\mathrm{NaCl}\right.$, Prolabo) was used as the electrolyte. Copper acetate $\left(\mathrm{C}_{4} \mathrm{H}_{6} \mathrm{CuO}_{4} \cdot \mathrm{H}_{2} \mathrm{O}\right.$, $100 \%$, UCB $)$, ethynylferrocene $\left(\mathrm{C}_{12} \mathrm{H}_{10} \mathrm{Fe}, 97 \%\right.$, Aldrich) and ascorbic acid $\left(\mathrm{C}_{6} \mathrm{H}_{8} \mathrm{O}_{6}, 99.7 \%\right.$, Merck) were used in the Huisgen cycloaddition reaction. Sodium diethyldithiocarbamate trihydrate $\left(\mathrm{C}_{5} \mathrm{H}_{10} \mathrm{NNaS}_{2} .3 \mathrm{H}_{2} \mathrm{O}\right.$, ACS reagent, Merck) was used to remove copper traces from the electrode after the click reaction. 3-azidopropyltrimethoxysilane (AzPTMS) was synthesised as described previously. ${ }^{[31]}$

\subsection{Electrochemical measurements}

EASA and cyclic voltammetry experiments were carried out on a PGSTAT 100 potentiostat (Autolab, Netherlands). A three-electrode system was used with an $\mathrm{Ag} / \mathrm{AgCl}(3 \mathrm{M} \mathrm{KCl})$ reference electrode (Metrohm) and a stainless-steel rod as the counter electrode, and ITO plates as working electrode, modified with mesoporous silica thin films (unless stated otherwise). Chronoamperometry performed in the flow cell was measured using a PGSTAT302N potentiostat (Autolab, Netherlands).

\subsection{Preparation of the mesoporous silica thin films}

Mesoporous silica films were prepared by EASA as described previously. ${ }^{[27]} \mathrm{A}$ sol was prepared with $100 \mathrm{mM}$ TEOS, $32 \mathrm{mM}$ CTAB in $0.1 \mathrm{M} \mathrm{NaNO}_{3}$ in an ethanol: water 1:1 v/v ratio. The $\mathrm{pH}$ of the sol was adjusted to 3 by the addition of $\mathrm{HCl}$. The sol was left to hydrolyse for $2.5 \mathrm{~h}$ before electrodeposition. The sol was prepared on a daily basis. A potential of $-1.3 \mathrm{~V}$ was applied for $20 \mathrm{~s}$ (using an ITO plate as working electrode of a surface area of $0.502 \mathrm{~cm}^{2}$ ), a silver wire as a pseudo-reference electrode and a stainless-steel mesh as a counter electrode). After the film formation, the electrodes were kept at $130{ }^{\circ} \mathrm{C}$ for 16 hours to ensure good cross-linking of the silica network. Surfactant template was removed by immersion in $0.1 \mathrm{M} \mathrm{HCl}$ in ethanol for 30 minutes. Mesoporous silica films were further characterized by electrochemistry (surface area exposed for the characterisation and cysteine detection work was $0.188 \mathrm{~cm}^{2}$ ), grazingincidence small-angle scattering (GISAXS), and transmission electron microscopy (TEM) as described in the supplementary information section (Figures S1-4 and associated text). The level of mesostructural order was evaluated by TEM using a Philips CM20 microscope at an acceleration voltage of $200 \mathrm{kV}$. The samples were prepared by removing some pieces of the films, which were supported on a carbon-coated copper grid. 


\subsection{Functionalisation of the mesoporous silica thin films}

The ferrocene-functionalized films were prepared in a two-step procedure described previously. ${ }^{[31]}$ The first step consisted of the co-condensation by electrochemically assisted self-assembly from a sol prepared with a 70 / 30 molar ratio of TEOS / AzPTMS (total silane concentration was 100 or $200 \mathrm{mM}$ ). The CTAB / silane ratio was kept at 0.32 . Other parameters are the same as for the non-functionalised films (section 2.2). After electrogeneration, the films were cured in the oven $\left(16 \mathrm{~h}\right.$ at $\left.130{ }^{\circ} \mathrm{C}\right)$; the template was extracted in $0.1 \mathrm{M} \mathrm{HCl}$ in ethanol. The second step of the synthesis consisted on the Huisgen cycloaddition reaction leading to the coupling of the azide- and alkyne-bearing molecules, catalysed by $\mathrm{Cu}(\mathrm{l})$ ions, to form a triazole core substituted in the 4 position. The azide-functionalised films were immersed for $24 \mathrm{~h}$ (in the dark at room temperature) in a solution of $\mathrm{BuOH} / \mathrm{H}_{2} \mathrm{O}(6 / 4 ; 20 \mathrm{~mL}$ ) of ethynylferrocene $(10.0 \mathrm{mg}), \mathrm{CuSO}_{4}, \mathrm{H}_{2} \mathrm{O}(2.0 \mathrm{mg})$ and ascorbic acid $(10.5 \mathrm{mg})$. This reaction led to the derivatisation of the azide-based films via 'click chemistry' into ferrocenefunctionalized films. The film were then thoroughly rinsed with water, ethanol and acetonitrile (10 min in each solvent) to remove unreacted species and traces of catalyst. The films were then kept in $0.05 \mathrm{M}$ Sodium diethyldithiocarbamate solution in ethanol for $30 \mathrm{~min}$ to remove any traces of copper. The films are subsequently dried for $30 \mathrm{~min}$ in the dark. IR characterization of the synthesised films are shown in Figure S5, demonstrating the successful click coupling.

\subsection{Flow injection analysis}

The flow injection cell was purchased from $\mathrm{BASi}^{\circledR}$ (USA). An ITO electrode modified with ferrocene-functionalized mesoporous silica film, according to section 2.4 , was used as a working electrode $\left(A=0.407 \mathrm{~cm}^{2}\right) . \mathrm{An} \mathrm{Ag} / \mathrm{AgCl} / 1 \mathrm{M} \mathrm{KCl}$ was used a reference electrode and the stainless-steel body of the flow cell was used as the counter electrode. The total volume of the flow cell chamber was $2.22 \mathrm{~mL}$. Flow injection analysis was performed in amperometric mode with an applied potential of $+0.65 \mathrm{~V}$ while injection $150 \mu \mathrm{L}$ aliquots of thiol at the desired concentration. The flow rate of the buffer electrolyte solution $(0.1 \mathrm{M}$ bis-tris $+0.1 \mathrm{M} \mathrm{NaCl})$ was $1 \mathrm{~mL} \mathrm{~min}-1$. The buffer solution and the aliquots of cysteine were degassed by bubbling $\mathrm{N}_{2}$ to remove dissolved oxygen and hence avoid oxidation of thiol. 


\section{Results and Discussion}

\subsection{Thiol oxidation mediated by $\mathrm{Fc}(\mathrm{MeOH})_{2}$ at mesoporous silica film electrodes}

Mesoporous silica films were electrogenerated according to the described procedure. The quality and integrity of the films were assessed by a string of characterisation techniques (Figures S1-4). The EASA method has led to the formation of about $100 \mathrm{~nm}$ thick films with mesopores of $2.4 \mathrm{~nm}$ in diameter. Those pores are organised in a hexagonal compact arrangement and are oriented perpendicular to the electrode surface, allowing efficient mass transport of molecules from the bulk of the solution to the electrode surface, through the mesoporous silica films. ${ }^{[29]}$ Figure $1 \mathrm{~A}$ shows the cyclic voltammetry of $0.5 \mathrm{mM}$ of $\mathrm{Fc}(\mathrm{MeOH})_{2}$ at an electrode modified with mesoporous silica film, which occurred at $E_{1 / 2}=+0.252 \mathrm{~V}$. The addition of $1.25 \mathrm{mM}$ of cysteine to the solution led to the increase of the forward current and the decrease of the reverse peak current. The $\mathrm{Fc}(\mathrm{MeOH})_{2}{ }^{+}$formed at the electrode surface transferred an electron with cysteine, and was reduced back to $\mathrm{Fc}(\mathrm{MeOH})_{2}$. $\mathrm{Fc}(\mathrm{MeOH})_{2}$ was then regenerated at the electrode surface, causing the rise in forward peak current, in good agreement with an EC' mechanism. ${ }^{[48]}$ Similar results were observed when $1.49 \mathrm{mM}$ of glutathione was added, indicating that the oxidation of the thiol function of glutathione could be oxidised in the same way as the one of cysteine. The difference in thiol concentration led to a faster drop in current observed for cysteine (Figure 1A) than for glutathione (Figure 1B).
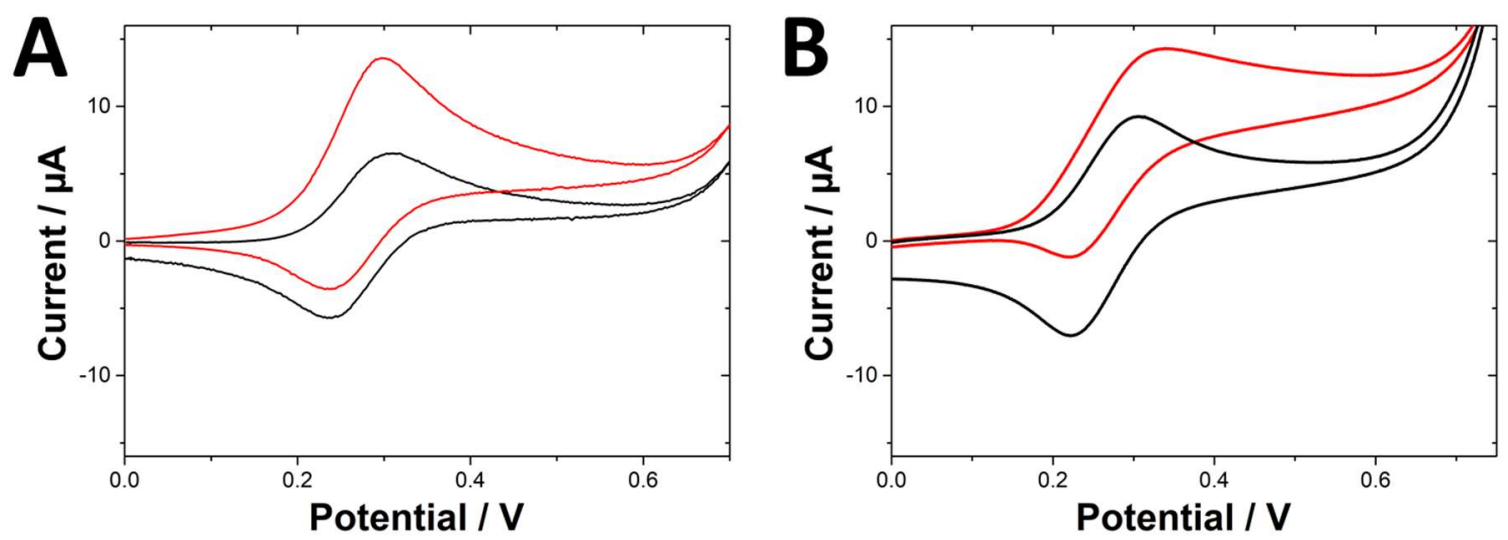

Figure 1: Cyclic voltammetry at a mesoporous silica film electrode of $0.5 \mathrm{mM}$ of $\mathrm{Fc}(\mathrm{MeOH})_{2}$ in the absence (black curve) and in the presence (red curve) of (A) $1.25 \mathrm{mM}$ cysteine and (B) 1.49 mM glutathione. $v=10 \mathrm{mV} \mathrm{s}^{-1}$.

The scan rate was varied to understand the effect of reaction time on the voltammetric response of a solution of $0.5 \mathrm{mM}$ of $\mathrm{Fc}(\mathrm{MeOH})_{2}$ in the presence of $1.25 \mathrm{mM}$ cysteine at a 
mesoporous silica electrode (Figure 2). At $10 \mathrm{mV} \mathrm{s}^{-1}$, the reverse peak is much smaller with a ratio of forward peak current over reverse peak current, $i_{f} / i_{r}=1.9$. The forward current increased with the scan rate along with the appearance of a larger current in the reverse scan, indicating that the overall reaction kinetics was limited by the rate of electron transfer between the thiol group and the redox mediator and not by the electron transfer between the redox mediator and the electrode. Figure 3 showed the $i_{f} / i_{r}$ ratio for concentrations of cysteine of 1.25 and $4.5 \mathrm{mM}$, at scan rates varied between $10 \mathrm{mV} \mathrm{s}^{-1}$ to $1 \mathrm{~V} \mathrm{~s}^{-1}$. Those were compared to the reversible signal observed in the absence of cysteine (data shown as discs on Figure 3). For both cysteine concentrations, the $i_{f} / i_{r}$ ratio decreased as the scan rate increased, to reach unity at the fastest scan rate of $1 \mathrm{~V} \mathrm{~s}^{-1}$. At such a scan rate, only the reversible electrochemical response of $\mathrm{Fc}(\mathrm{MeOH})_{2}$ was observed and no cysteine oxidation.

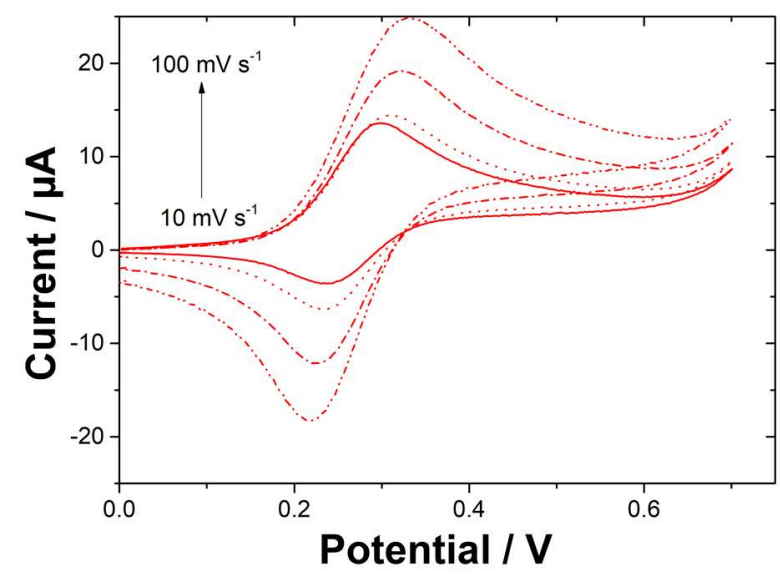

Figure 2: Cyclic voltammetry at a mesoporous silica film electrode of $0.5 \mathrm{mM}$ of $\mathrm{Fc}(\mathrm{MeOH})_{2}$ in the presence of $1.25 \mathrm{mM}$ cysteine. $v=10 ; 20 ; 50$ and $100 \mathrm{mV} \mathrm{s}^{-1}$.

The $i_{f} / i_{r}$ ratio was also compared at both bare and modified electrode $s$ (Figure 3 ). The current ratio was slightly lower at the electrodes modified with mesoporous silica film than at bare ITO electrodes, suggesting that the presence of the film impacted somewhat the overall kinetics of the reaction. The most likely reason for slower kinetics would be mass transport limitation of cysteine within the pores, despite their orientation perpendicular to the electrode surface (Figures S2-3). 


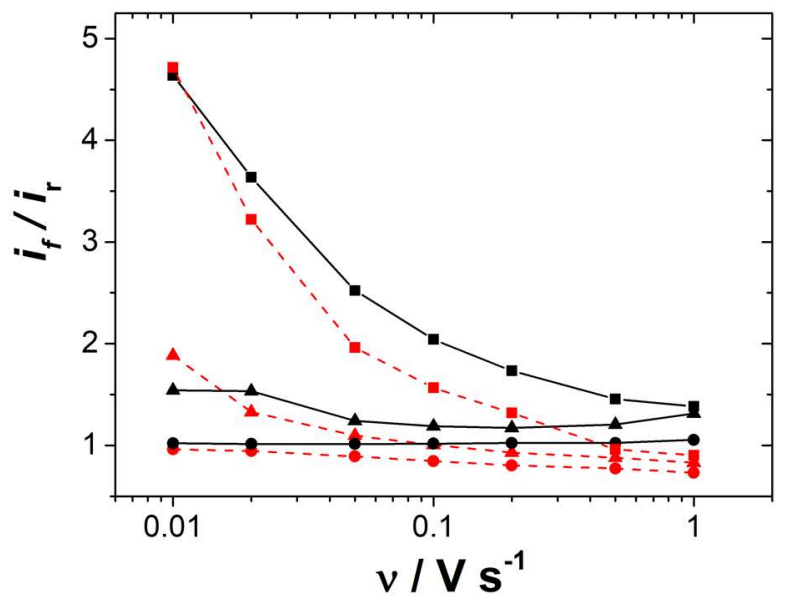

Figure 3: Ratio of the forward peak current / reverse peak current, $i_{f} / i_{r}$, as a function of the scan rate extracted from cyclic voltammograms obtained at bare ITO electrode (black solid lines) and at mesoporous silica film electrodes (red dashed electrodes) with $0.5 \mathrm{mM}$ $\mathrm{Fc}(\mathrm{MeOH})_{2}$. Cysteine concentration was 0 (discs), 1.25 (triangles) and 4.5 (squares) mM.

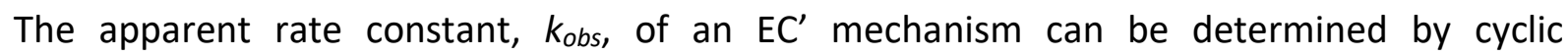
voltammetry. ${ }^{[49]}$ Based on the scan rate studies (Figure 2), we assumed that the electron transfer for the ferrocene/ferrocenium redox couple was fast and that the rate determining step was the electron transfer between the ferrocenium and the thiol group. $k_{o b s}$ was determined in a large excess of thiol $(\gamma=100)$ at a bare ITO electrode (black curves on Figure 4). In such cases, the catalytic current, $i_{c}$, reached a steady-state, which can be described by equation (1):

$$
i_{c}=n F A C_{\mathrm{Fc}(\mathrm{MeOH})_{2}}^{0} \sqrt{D k_{\text {obs }}}
$$

Where $n$ is the number of electron transferred in the reaction, $F$ the faraday constant, $A$ the electrode surface area $\left(0.188 \mathrm{~cm}^{2}\right), \mathrm{C}_{\mathrm{Fc}(\mathrm{MeOH})_{2}}^{0}$ the bulk concentration of $\mathrm{Fc}(\mathrm{MeOH})_{2}$ (in mol $\left.\mathrm{cm}^{-3}\right), D$ the diffusion coefficient for $\mathrm{Fc}(\mathrm{MeOH})_{2}\left(7 \times 10^{-7} \mathrm{~cm}^{2} \mathrm{~s}^{-1}\right) . k_{o b s}$ can be deduced from equation (1) and the intrinsic rate constant of the electron transfer between the thiol and the ferrocenium ion, $k_{e}$, can be determined from equation (2):

$$
k_{o b s}=k_{e} C_{\text {thiol }}^{0}
$$

Based on equations (1) and (2) $k_{o b s}$ and $k_{e}$ were determined for the oxidation of cysteine and glutathione at the bare ITO electrode using $i_{c}$ values at $E=+0.45 \mathrm{~V}$ for a series $(N=6)$ of scan rates between 10 and $100 \mathrm{mV} \mathrm{s}^{-1}$ (Table 1). The electron transfer between cysteine and 
ferrocenium ion was 3.5 times faster than between the glutathione and the ferrocenium ion. Such a significant difference between the intrinsic rate constants could be attributed to the difference between the pKa of the buffer molecules (bis-Tris, pKa $=6.5$ ) and the one of the thiol molecules (pKa(Cysteine) $=8.1 ; \mathrm{pKa}($ Glutathione $)=9.2) .^{[50]}$

Table 1: Apparent and intrinsic rate constants determined for cysteine and glutathione mediated oxidation by $\mathrm{Fc}(\mathrm{MeOH})_{2}$ at a bare ITO electrode.

\begin{tabular}{|c|c|c|c|}
\hline Analyte & $\begin{array}{c}i_{c} \\
\mu A^{a}\end{array}$ & $\begin{array}{l}K_{o b s} \\
s^{-1}\end{array}$ & $\begin{array}{c}k_{e} \\
L \mathrm{~mol}^{-1} \mathrm{~s}^{-1}\end{array}$ \\
\hline Cysteine & $11.3 \pm 0.2$ & $7.9 \pm 0.2$ & $(9.5 \pm 0.3) \times 10^{5}$ \\
\hline Glutathione & $6.0 \pm 0.1$ & $2.2 \pm 0.1$ & $(2.7 \pm 0.1) \times 10^{5}$ \\
\hline
\end{tabular}

a: measured at $E=+0.45 \mathrm{~V} ;{ }^{\mathrm{b}}: i_{c}$ measured at the electrode modified with mesoporous silica.

For large excess of cysteine $(\gamma=100), i_{c}$ was lower at the modified electrode than the bare ITO electrode, throughout the $10-100 \mathrm{mV} \mathrm{s}^{-1}$ scan rate range. Such results are consistent with the ones observed in lower excess of cysteine $(\gamma=2.5$ and 9) as shown in Figure 3. For glutathione, the presence of the film has little impact between on the catalytic current recorded, unlike for cysteine where the catalytic peak current was smaller at the modified electrode than at the bare one (Figure 4). The difference of impact of the presence of the film on the catalytic current for the oxidation of cysteine mediated by $\mathrm{Fc}(\mathrm{MeOH})_{2}$ can be attributed to the difference of rate constants for glutathione and cysteine. The cysteine catalytic peak current decreased by $32 \%$ when a mesoporous silica film was present. The oxidised form of $\mathrm{Fc}(\mathrm{MeOH})_{2}$ was cationic and accumulated within the negatively charged silica walls. Diffusion of both $\mathrm{Fc}(\mathrm{MeOH})_{2}{ }^{+}$and cysteine through the silica film was slower than in the bulk. This mass transfer limitations due to the presence of the mesoporous silica film contributed to a reduced catalytic current. In the case of glutathione, mass transfer is also limited by the presence of silica film on the electrode. However, as the electron transfer reaction between the thiol and $\mathrm{Fc}(\mathrm{MeOH})_{2}$ is already slow as the bare electrode experiments showed, this mass transfer limitation did not to affect the electrocatalytic reaction. 

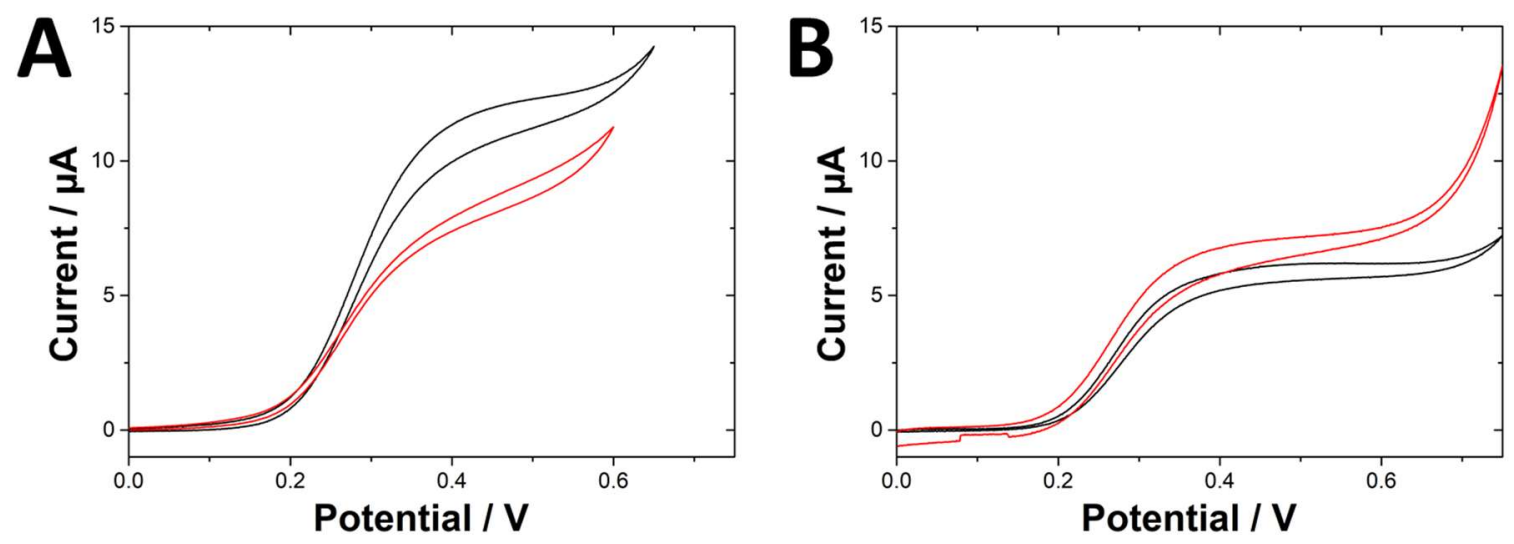

Figure 4: Cyclic voltammetry of $0.083 \mathrm{mM}$ of $\mathrm{Fc}(\mathrm{MeOH})_{2}$ for a large excess of $(\mathrm{A})$ cysteine $(\gamma=$ 100 ) and (B) glutathione at a bare electrode (black curve) and at a mesoporous silica film electrode (red curve). $v=10 \mathrm{mV} \mathrm{s}^{-1}$.

Despite the different apparent reaction rates for both glutathione and cysteine, the presence of a mesoporous silica film was not sufficient to selectively detect cysteine over glutathione. The further step was to immobilise ferrocene groups inside the silica mesochannels to induce the desired selectivity.

\subsection{Cysteine oxidation mediated by ferrocene-functionalised mesoporous silica films}

The electrochemistry of mesoporous silica film functionalised with ferrocene groups is shown in Figure 5, in good agreement with previous works. ${ }^{[31,51,52]}$ The successful grafting of the ferrocene groups is confirmed by the presence of reversible signal. The amount of ferrocene moieties immobilised on in the silica channels has two effects. ${ }^{[51]} \mathrm{A}$ high density of ferrocene groups ensured a good rate of electron hopping between the ferrocene groups located close to the electrode surface and the ones further away, that cannot undergo direct electron transfer with the electrode surface. Yet, the charge transfer process operating at such rigid network bearing ferrocene moieties covalently bonded to the isolating silica material (i.e., electron hopping) is much slower than the direct oxidation of soluble ferrocene derivatives on ITO electrode. ${ }^{8}$ The oxidation of the ferrocene groups in the mesopore channels has led to the formation of ferrocenium groups and the generation of a positive charge that can only be counterbalanced by the ingress of an anion of the background electrolyte. ${ }^{[51]}$ However, the high content of ferrocene attached to the silica walls can limit mass transport of redox species (such as $\left.\mathrm{Ru}\left(\mathrm{NH}_{3}\right)_{6}{ }^{3+}\right)^{[31]}$ or of counter anions. ${ }^{[51]}$ We selected a ratio of AzPTMS:TEOS of 30:70 to form a film with a high content of ferrocene group, with the purpose of serving the following 
two objectives: (i) to ensure an efficient electron hopping in order to keep satisfactory sensitivity; and (ii) to allow the mass transport of cysteine within the mesochannels and to hinder the mass transport of the bulkier glutathione, in order to achieve selectivity. This was demonstrated by the cyclic voltammograms recorded upon addition of thiol to the solution. In the case of additions of 196 and $281 \mu \mathrm{M}$ of cysteine to the solution, the forward peak current rose from $0.93 \mu \mathrm{A}$ in the absence of cysteine to 1.13 and $1.34 \mu \mathrm{A}$, while the reverse peak current decreased (Figure 5A). This behaviour was similar than the one reported when $\mathrm{Fc}(\mathrm{MeOH})_{2}$ was diffusing freely in solution (see section 3.1), suggesting that cysteine could diffuse through the mesochannels to transfer an electron with ferrocenium, undergoing an $E C^{\prime}$ mechanism. However, in the case of the addition of the same concentrations of glutathione (Figure 5B), there was no significant changes in the cyclic voltammograms. The limited mass transport of glutathione through the functionalised pores did not allow electron transfer between ferrocenium moieties and glutathione. Another possible effect that can contribute to explain such difference is the aforementioned slower rate constants observed for the mediated oxidation of glutathione (compared to cysteine) by ferrocene dimethanol (Table 1), which should be even accentuated when using the ferrocene functionalised film characterised by slower charge transfer by electron hopping. The selective detection of cysteine was then possible using mesoporous silica films modified with ferrocene.
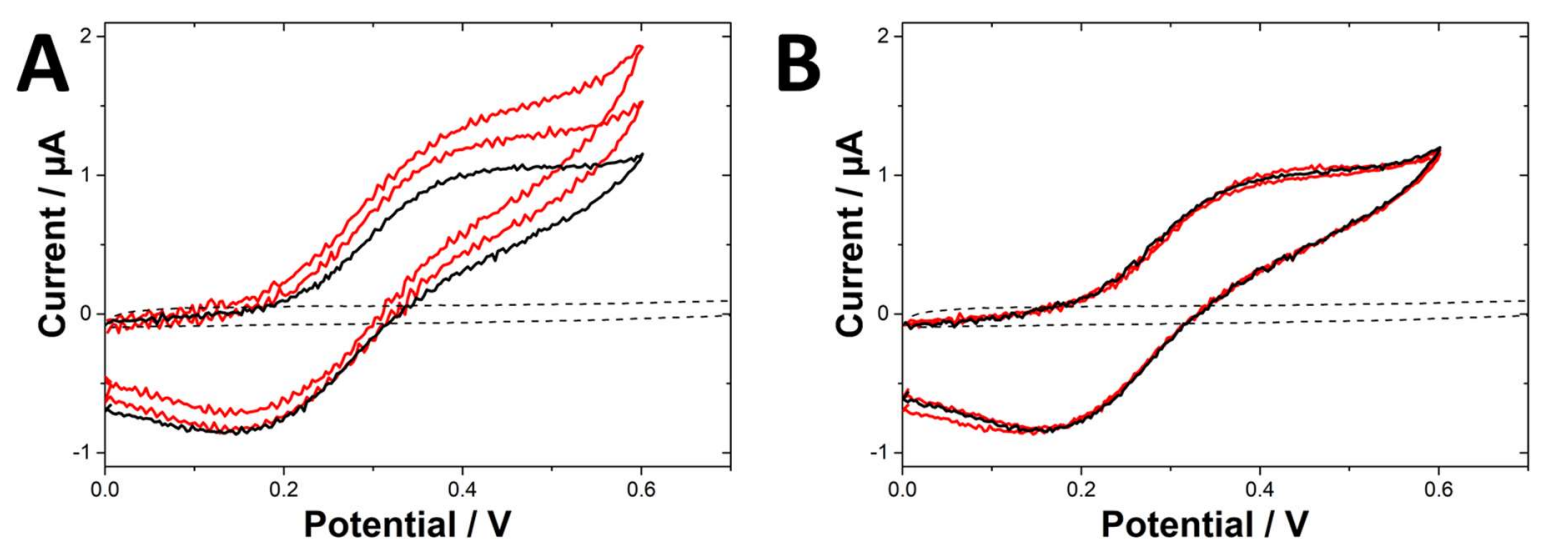

Figure 5: Cyclic voltammetry at an electrode modified with a mesoporous silica film functionalised with ferrocene with additions of 196 and $281 \mu \mathrm{M}$ of (A) cysteine and (B) glutathione. $v=10 \mathrm{mV} \mathrm{s}^{-1}$. Black curves represent the cyclic voltammograms in the absence of thiol and dashed curves represent the electrochemical response when no ferrocene moieties were immobilised. 
An electrode modified with a film functionalised with ferrocene was then used as a working electrode in a flow cell that was elaborated for other purposes in a previous study. ${ }^{[52]} A$ potential of $+0.65 \mathrm{~V}$ was applied to oxidise the ferrocene moieties immobilised in the mesopores. The applied potential was determined after recording the CV of the modified electrode in the flow cell (Figure S6). When cysteine was injected in the flow cell, a rise in current was observed (Figure 6A), which was the result of the electron transfer from cysteine to the ferrocenium and causing the re-oxidation of ferrocene. The peak current increased linearly $\left(I_{\text {peak }}=1.28 \times 10^{-3}[\mathrm{Cys}]+1.39 \times 10^{-2}, R^{2}=0.988\right)$ with the concentration of cysteine injected, which ranged from 3-20 $\mu \mathrm{M}$. Over the 20-100 $\mu \mathrm{M}$ concentration range, the slope of the calibration curve dropped to $0.68 \times 10^{-3} \mathrm{~A} \mathrm{M}^{-1}$. Despite a large background noise originating from the flow cell, a good repeatability of the peak current was observed with a relative standard deviation for the measurements of $3-12 \%$. The analytical performances of the mesoporous silica film functionalised with ferrocene compared well with the modified electrodes already reported in the literature (Table SI1). ${ }^{[14-16,18,20,21,23-26]}$
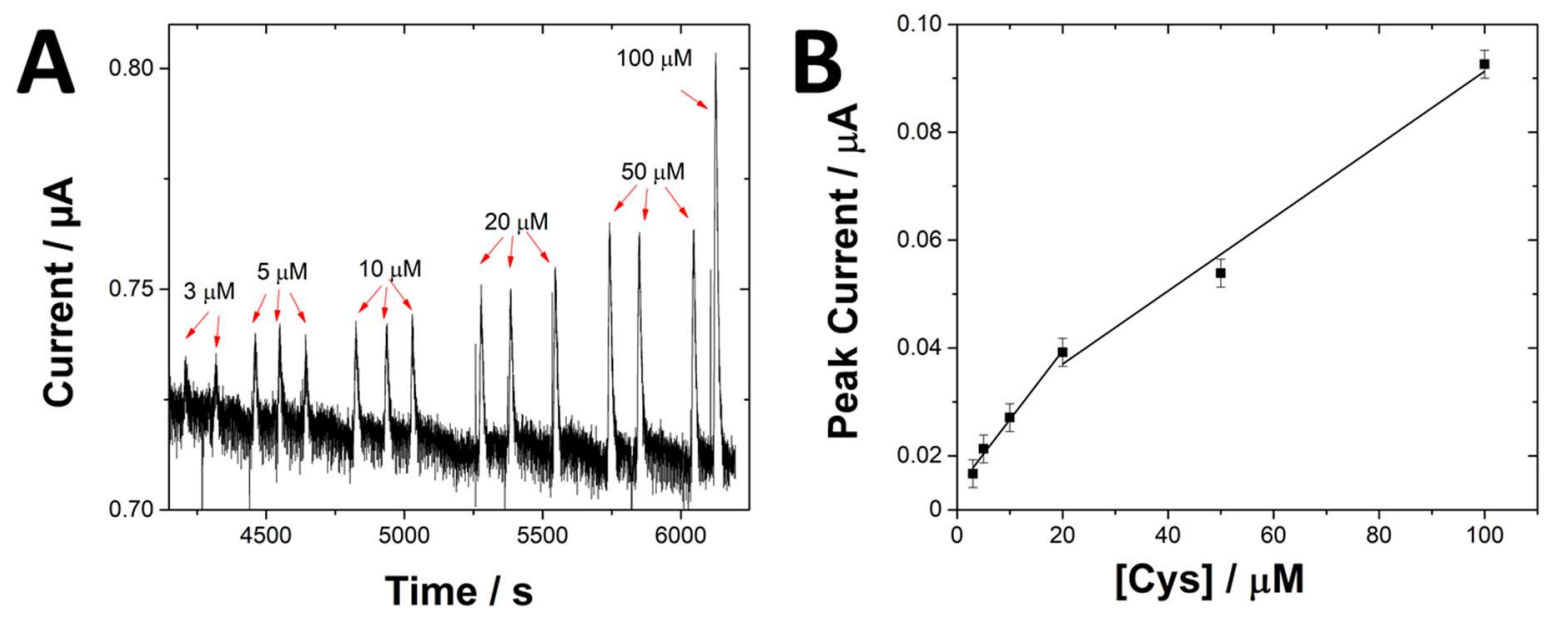

Figure 6: (A) Chronoamperograms obtained for increasing concentrations of cysteine (3-100 $\mu \mathrm{M})$. $E_{\text {applied }}=+0.65 \mathrm{~V}$; flow rate was $1 \mathrm{~mL} \mathrm{~min}^{-1}$. (B) Calibration curve showing peak current as a function of cysteine concentration.

Figure 7 showed the chronoamperogram for the injection of $50 \mu \mathrm{M}$ of glutathione (two first red arrows) and of cysteine (three last black arrows). For glutathione, the current recorded by approximately $10 \mathrm{nA}$ for a noise around $14 \mathrm{nA}$. The signal to noise ratio calculated from Figure 7 was lower than 1 while a species is considered to be statistically detectable if the signal to noise ratio is greater than 3 . When the same concentration of cysteine $(50 \mu \mathrm{M})$ was injected in the flow injection analysis system, the current measured rose by $53 \mathrm{nA}$, which gave a signal 
to noise ratio greater than 3, confirming the idea of a good selectivity for cysteine over glutathione as previously suggested from CV experiments (Figure 5).

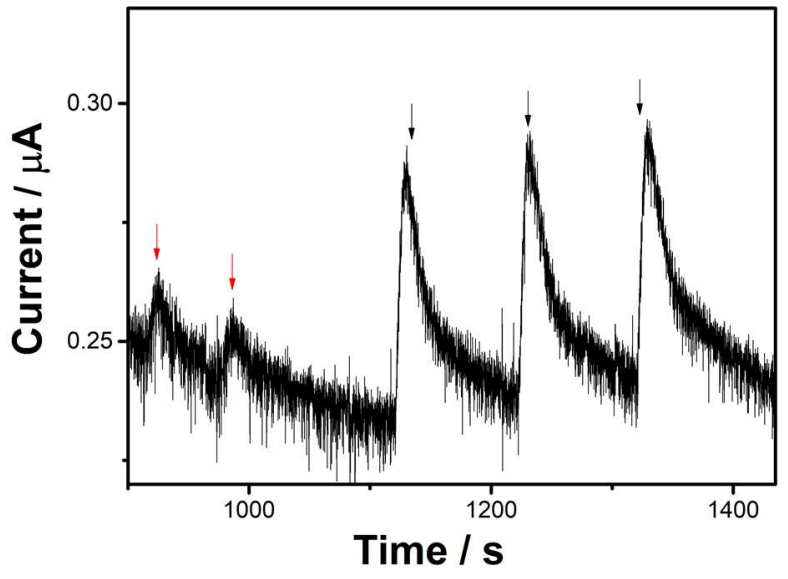

Figure 7: Chronoamperograms showing the flow injection analysis of $50 \mu \mathrm{M}$ of glutathione (red arrows) and of cysteine (black arrows). Eapplied $=+0.65 \mathrm{~V}$; flow rate was $1 \mathrm{~mL} \mathrm{~min}^{-1}$.

\section{Conclusions}

The thiol function of cysteine and of glutathione can be oxidised by $\mathrm{Fc}(\mathrm{MeOH}) 2^{+}$generated at the surface of a mesoporous silica electrode. The overall kinetics of this reaction was limited by the electron transfer between $\mathrm{Fc}(\mathrm{MeOH})_{2}{ }^{+}$and the thiol. Such an electron transfer was faster with cysteine than with glutathione. By immobilising the redox mediator inside silica mesochannels, the slow kinetics of glutathione oxidation were exploited to selectively detect cysteine. Indeed, the presence of cysteine in solution was oxidised at ferrocene-functionalised films while glutathione was not. The combination of charge transfer kinetic and mass transport limitations allowed the selectivity of the ferrocene-functionalised electrode for cysteine over glutathione.

\section{Acknowledgements}

This work was supported partly by the French PIA project "Lorraine Université d'Excellence" (Reference $\mathrm{N}^{\circ}$ ANR-15-IDEX-04-LUE). M Lionel Richaudeau is thanked for his help with the GISAXS measurements. 


\section{Keywords}

Cysteine detection; Ferrocene mediator; Film electrode; Mesoporous silica; Selectivity

\section{References}

[1] N. H. P. Cnubben, I. M. C. M. Rietjens, H. Wortelboer, J. van Zanden, P. J. van Bladeren, Environ. Toxicol. Pharmacol. 2001, 10, 141-152.

[2] K. K. Dennis, Y.-M. Go, D. P. Jones, J. Nutr. 2019, 149, 553-565.

[3] M. H. Stipanuk, J. E. Dominy, J.-I. Lee, R. M. Coloso, J. Nutr. 2006, 136, 1652S-1659S.

[4] H. Liu, H. Wang, S. Shenvi, T. M. Hagen, R. M. Liu, Ann. N. Y. Acad. Sci. 2004, 1019, 346-349.

[5] S. Whillier, J. E. Raftos, P. W. Kuchel, Redox Rep. 2008, 13, 277-282.

[6] A. E. Lang, Neurology 2007, 68, 948-952.

[7] D. Long, H. Wu, A. W. Tsang, L. B. Poole, B. K. Yoza, X. Wang, V. Vachharajani, C. M. Furdui, C. E. McCall, Sci. Rep. 2017, 7, 11005.

[8] K. Lertratanangkoon, C. J. Wu, N. Savaraj, M. L. Thomas, Cancer Lett. 1997, 120, 149156.

[9] L. Pendyala, S. Velagapudi, K. Toth, J. Zdanowicz, D. Glaves, H. Slocum, R. Perez, R. Huben, P. J. Creaven, D. Raghavan, Clin. Cancer Res. 1997, 3, 793-798.

[10] T. R. Ralph, M. L. Hitchman, J. P. Millington, F. C. Walsh, J. Electroanal. Chem. 1994, $375,1-15$.

[11] P. C. White, N. S. Lawrence, J. Davis, R. G. Compton, Electroanalysis 2002, 14, 89.

[12] N. Spãtaru, B. V. Sarada, E. Popa, D. A. Tryk, A. Fujishima, Anal. Chem. 2001, 73, 514519.

[13] L. Rojas, L. Molero, R. A. Tapia, R. del Rio, M. A. del Valle, M. Antilén, F. Armijo, Electrochim. Acta 2011, 56, 8711-8717. 
[14] P. Abiman, G. G. Wildgoose, R. G. Compton, Electroanalysis 2007, 19, 437-444.

[15] P. T. Lee, D. Lowinsohn, R. G. Compton, Electroanalysis 2014, 26, 1488-1496.

[16] G. Hignett, S. Threlfell, A. J. Wain, N. S. Lawrence, S. J. Wilkins, J. Davis, R. G. Compton, M. F. Cardosi, Analyst 2001, 126, 353-357.

[17] P. Song, A. C. Fisher, J. D. Wadhawan, J. J. Cooper, H. J. Ward, N. S. Lawrence, RSC Adv. 2016, 6, 70237-70242.

[18] P. T. Lee, J. E. Thomson, A. Karina, C. Salter, C. Johnston, S. G. Davies, R. G. Compton, Analyst 2015, 140, 236-242.

[19] F. Ricci, F. Arduini, A. Amine, D. Moscone, G. Palleschi, J. Electroanal. Chem. 2004, 563, 229-237.

[20] W. Y. Su, S. H. Cheng, Electrochem. Commun. 2008, 10, 899-902.

[21] Y. P. Hsiao, W. Y. Su, J. R. Cheng, S. H. Cheng, Electrochim. Acta 2011, 56, 6887-6895.

[22] L. L. Okumura, N. R. Stradiotto, N. V. Rees, R. G. Compton, Electroanalysis 2008, 20, 916-918.

[23] P. T. Lee, R. G. Compton, Electroanalysis 2013, 25, 1613-1620.

[24] C. C. Corrêa, S. A. V. Jannuzzi, M. Santhiago, R. A. Timm, A. L. B. Formiga, L. T. Kubota, Electrochim. Acta 2013, 113, 332-339.

[25] S. M. Chen, J. Y. Chen, R. Thangamuthu, Electroanalysis 2008, 20, 1565-1573.

[26] K. A. Joshi, P. C. Pandey, W. Chen, A. Mulchandani, Electroanalysis 2004, 16, 19381943.

[27] A. Walcarius, E. Sibottier, M. Etienne, J. Ghanbaja, Nat. Mater. 2007, 6, 602-608.

[28] Z. Teng, G. Zheng, Y. Dou, W. Li, C.-Y. Y. Mou, X. Zhang, A. M. Asiri, D. Zhao, Angewan. Chem. Int. Ed. 2012, 51, 2173-2177.

[29] A. Goux, M. Etienne, E. Aubert, C. Lecomte, J. Ghanbaja, A. Walcarius, Chem. Mater. 2009, 21, 731-741.

[30] N. Vilà, E. André, R. Ciganda, J. Ruiz, D. Astruc, A. Walcarius, Chem. Mater. 2016, 28, 
2511-2514.

[31] N. Vilà, J. Ghanbaja, E. Aubert, A. Walcarius, Angewan. Chem. Int. Ed. 2014, 53, 294550.

[32] M. Rafiee, B. Karimi, Y. A. Asl, H. Vali, Analyst 2013, 138, 1740-1744.

[33] N. Vilà, J. Ghanbaja, A. Walcarius, Adv. Mater. Interfaces 2016, 3, 1500440.

[34] A. Walcarius, Electroanalysis 2015, 27, 1303-1340.

[35] F. Yan, X. Lin, B. Su, Analyst 2016, 141, 3482-3495.

[36] A. Walcarius, Curr. Opin. Electrochem. 2018, 10, 88-97.

[37] P. Zhou, L. Yao, K. Chen, B. Su, Crit. Rev. Anal. Chem. 2020, https://doi.org/10.1080/10408347.2019.1642735.

[38] T. Nasir, N. A. Vodolazkaya, G. Herzog, A. Walcarius, Electroanalysis 2019, 31, 202207.

[39] K. P. Singh, M. Kumar, Lab Chip 2012, 12, 1332-1339.

[40] T. Nasir, G. Herzog, M. Hébrant, C. Despas, L. Liu, A. Walcarius, ACS Sensors 2018, 3, 484-493.

[41] N. Vilà, P. de Oliveira, A. Walcarius, I. M. Mbomekallé, Electrochim. Acta 2019, 309, 209-218.

[42] M. Y. Chen, M. J. Sailor, Anal. Chem. 2011, 83, 7186-7193.

[43] D. Basnig, N. Vilá, G. Herzog, A. Walcarius, J. Electroanal. Chem. 2020, doi: 10.1016/j.jelechem.2020.113993.

[44] M. Etienne, A. Quach, D. Grosso, L. Nicole, C. Sanchez, A. Walcarius, Chem. Mater. 2007, 19, 844-856.

[45] W. Li, L. Ding, Q. Wang, B. Su, Analyst 2014, 139, 3926-3931.

[46] X. Lin, Q. Yang, L. Ding, B. Su, ACS Nano 2015, 9, 11266-11277.

[47] M. B. Serrano, C. Despas, G. Herzog, A. Walcarius, Electrochem. Commun. 2015, 52, 34-36. 
[48] J. M. Savéant, K. B. Su, J. Electroanal. Chem. 1984, 171, 341-349.

[49] E. S. Rountree, B. D. McCarthy, T. T. Eisenhart, J. L. Dempsey, Inorg. Chem. 2014, 53, 9983-10002.

[50] D. R. Weinberg, C. J. Gagliardi, J. F. Hull, C. F. Murphy, C. A. Kent, B. C. Westlake, A. Paul, D. H. Ess, D. G. McCafferty, T. J. Meyer, Chem. Rev. 2012, 112, 4016-4093.

[51] N. Vilà, A. Walcarius, Electrochim. Acta 2015, 179, 304-314.

[52] C. Karman, N. Vilà, C. Despas, A. Walcarius, Electrochim. Acta 2017, 228, 659-666. 